\title{
An evaluation of the factors that affect the health-related quality of life of children following myelosuppressive chemotherapy
}

\author{
Christina R. Baggott • Marylin Dodd • Christine Kennedy • Neyssa Marina • \\ Katherine K. Matthay • Bruce Cooper • Christine Miaskowski
}

Received: 13 August 2009 / Accepted: 18 January 2010/Published online: 16 February 2010

(C) The Author(s) 2010. This article is published with open access at Springerlink.com

\begin{abstract}
Purpose The purposes of this study, in children who were assessed 1 week after the administration of myelosuppressive chemotherapy were: to compare the total and subscale scores on a generic measure of health-related quality of life (HRQOL) to normative data from healthy children and describe the relationships between demographic, clinical, and symptom characteristics of children with cancer and generic and disease-specific dimensions of HRQOL.

Methods Patients $(n=61)$ were predominantly male $(52.5 \%)$, minority $(63.9 \%)$, and 14.7 years of age. Children completed the Memorial Symptom Assessment Scale for 10- to 18-year olds, the PedsQL ${ }^{\mathrm{TM}}$ Generic and Cancer Modules, and the Karnofsky Performance Status (KPS) scale 1 week after the start of a chemotherapy cycle.
\end{abstract}

C. R. Baggott $(\triangle) \cdot$ M. Dodd $\cdot$ C. Miaskowski

Department of Physiological Nursing, University of California, San Francisco,

2 Koret Way, Box 0610, San Francisco, CA 94143, USA

e-mail: christina.baggott@ucsf.edu

C. Kennedy

Department of Family Health Care Nursing,

University of California, San Francisco,

San Francisco, USA

N. Marina

Department of Pediatrics, Stanford University,

Stanford, USA

K. K. Matthay

Department of Hematology/Oncology, University of California,

San Francisco,

San Francisco, USA

B. Cooper

School of Nursing, University of California, San Francisco,

San Francisco, USA
Results The mean number of symptoms per patient was 10.6. Compared with the normative sample, children with cancer reported significantly lower scores for the total scale and all of the subscales except emotional and social functioning. No significant differences were found between any demographic characteristics and total or subscale scores on the generic or disease-specific measures of HRQOL. Lower KPS scores were associated with poorer generic and disease-specific HRQOL scores. In addition, a higher number of symptoms was associated with poorer generic and disease-specific HRQOL scores. Finally, higher symptom distress scores were associated with poorer generic and disease-specific HRQOL scores.

Conclusion Among the demographic, clinical, and symptom characteristics studied, poorer functional status and higher symptom burden were associated with significant decreases in HRQOL in children who received myelosuppressive chemotherapy.

Keywords Health-related quality of life $\cdot$ Karnofsky Performance Status · Myelosuppressive chemotherapy

\section{Introduction}

Collectively, the physical and psychosocial well-being of individuals receiving health care is termed health-related quality of life (HRQOL). This concept differs from the broader concept of overall quality of life which may include environmental, political, or economic issues in addition to health-related concerns [1]. The inclusion of HRQOL as an evaluable endpoint in cancer treatment and symptom management trials is important for a number of reasons. It can be used as part of an evaluation of the effectiveness of a treatment or to discriminate between two treatments with 
equivalent efficacy, but different toxicity profiles. This information can be used in a shared decision-making process with children and parents, because even small changes in HRQOL that occur early in a child's life may cause large cumulative effects over time in quality-of-life years lost [2].

Prior to 2000, very few clinical trials with pediatric oncology patients evaluated HRQOL as a study endpoint [3]. However, at the present time, many Phase III chemotherapy (CTX) trials collect data on HRQOL to supplement data on survival rates. In addition, HRQOL endpoints are being used in nearly $75 \%$ of oncology symptom management trials [4] as a result of a mandate by the Food and Drug Administration to include patient reported outcomes (PROs) in clinical trials $[5,6]$.

Most HRQOL research in pediatric oncology focuses on survivors of childhood cancer [7]. Only a limited number of studies have identified the factors that affect HRQOL in children who are receiving active cancer treatment [8-17]. Only four of these studies included patients receiving intensive CTX $[8,10,15,18]$, and none included children who received only myelosuppressive CTX. Some information, albeit limited in quantity, is available regarding the relationships between demographic (e.g., age, gender) and clinical characteristics (e.g., treatment status, comparisons among various cancer diagnoses) and HRQOL of children who received cancer CTX. In addition, the relationships among functional status, symptom occurrence rates, and HRQOL of children with cancer were assessed in only one study [19]. Therefore, the purposes of this study, in children who were assessed 1 week after the administration of myelosuppressive CTX were: to compare the total and subscale scores on a generic measure of HRQOL (i.e., the Pediatric Quality of Life Inventory 4.0 Generic Core Scale) to normative data from healthy children and to describe the relationships between demographic, clinical, and symptom characteristics of children with cancer and generic and disease-specific dimensions of HRQOL. It was hypothesized that the HRQOL scores of children with cancer would be lower than those of healthy children.

\section{Patients and methods}

Patients and procedures

This descriptive study used self-report questionnaires to obtain information from a convenience sample of children and adolescents with cancer (10 to 18 years of age) who were able to understand English or Spanish and give assent or consent to participate and were receiving myelosuppressive CTX. Participants were receiving CTX either as their initial therapy or for relapsed or refractory disease and had received at least one prior course of CTX. Children younger than 10 years of age were excluded because the instrument used to evaluate symptoms was validated in patients between the ages of 10 and 18 years.

Myelosuppressive CTX refers to treatment that is expected to cause a significant drop in the absolute neutrophil count to less than 500 cells $/ \mu \mathrm{L}$, with subsequent blood count recovery expected to occur within 3 to 4 weeks. Similar CTX regimens were targeted for selection among common diagnoses (e.g., doxorubicin with cisplatin for osteosarcoma and cyclophosphamide with cytarabine for acute lymphocytic leukemia). Patients were excluded if they were receiving concurrent radiation therapy. Patients were recruited from three pediatric oncology settings in the San Francisco Bay area.

Between February 2008 and February 2009, a total of 73 patients were approached to participate, and 66 provided assent or consent (response rate of $91.4 \%$ ). Of the eligible patients available, approximately eight were not approached because research staff were not available at the site. The primary reason for refusal was that patients were not interested in completing questionnaires. While data were collected weekly over a 3-week period (i.e., prior to the administration of CTX, 1 week following CTX administration, and 2 weeks following CTX administration), the HRQOL data reported in this paper is from the second time point (i.e., the week following CTX administration). Patients' symptoms were expected to be the most frequent and severe at this time point. In addition, previous research found the HRQOL of pediatric oncology patients was lowest in the days immediately following CTX [8].

The study was approved by the Human Subjects Committee at the University of California, San Francisco, and at each of the study sites. Patients' parents or guardians and patients who were 18 years of age signed a written, informed consent. Patients aged 10 to 17 (85\%) gave either written or verbal assent as per each institution's guidelines.

One week after the administration of CTX, children completed the Memorial Symptom Assessment Scale for 10- to 18-year olds (MSAS 10-18) [20]. In addition, they completed the age-appropriate versions of the Pediatric Quality of Life Inventory 4.0 Generic Core Scale (PedsQL ${ }^{\text {TM }}$ 4.0 GCS) [21, 22], the Pediatric Quality of Life Inventory 3.0 Cancer Module Scale (PedsQL ${ }^{\text {TM }} 3.0$ Cancer) [23], the Karnofsky Performance Status (KPS) scale [24], and a weekly data form to capture information not uniformly included in the medical record (e.g., number of hospitalizations, fever). Children were asked to respond to each question based on their experiences during the week following CTX administration. Children received support from the the research assistants to complete the study questionnaires as needed in person (if the patients were hospitalized or had clinic appointments) or via telephone. English and Spanish versions of the PedsQL ${ }^{\mathrm{TM}}$ were 
available. The MSAS 10-18 was translated from English to Spanish using forward and backward translation procedures. Patients' medical records were reviewed for disease and treatment information. The children were given a $\$ 50$ gift card to compensate them for their time.

\section{Instruments}

The revised version of the MSAS 10-18 assesses 31 symptoms on three dimensions. If patients reported the occurrence of a symptom over the previous week, they rated the symptom's frequency (1 (almost never) to 4 (almost always)), severity (1 (slight) to 4 (very severe)), and distress (0 (not at all) to 4 (very much)) using Likert scales. Positive responses were summed to determine the total number of symptoms experienced. Severity and distress ratings were assigned a value of zero when the symptom was not reported. The severity and distress ratings for all 31 symptoms were averaged to calculate the mean ratings for these two dimensions. The MSAS 10-18 was chosen because it is a multidimensional symptom inventory that evaluates 31 symptoms, yet can be completed in less than 15 min [20]. The MSAS 10-18 has established validity and reliability [20].

The PedsQL ${ }^{T M}$ is a modular instrument that consists of a generic measure and disease-specific modules. The generic version of the instrument (i.e., PedsQL 4.0 GCS) has been used extensively to assess HRQOL in both healthy and chronically ill children with a variety of medical conditions, including cancer. It is a 23-item instrument that evaluates the following dimensions of HRQOL: physical, emotional, social, and school functioning [21, 22]. In this study, the acute version of the instrument was used. Patients responded using the time frame of the past 7 days, using 5-point Likert scales (i.e., 0 (never a problem) to 4 (almost always a problem)). Items are reverse scored and linearly transformed to a 0 to 100 scale, with higher scores indicating a better HRQOL. A total and four subscale scores are calculated (i.e., physical functioning, emotional functioning, social functioning, school functioning).

The cancer-specific instrument used in this study was the PedsQL TM 3.0 Cancer Module Acute Version [23], a 27item multidimensional survey with eight subscales (i.e., pain and hurt, nausea, procedural anxiety, treatment anxiety, worry, cognitive problems, perceived physical appearance, communication). The response format and scoring procedures are similar to those for the PedsQL ${ }^{\text {TM }}$ 4.0 GCS.

Each of the HRQOL instruments takes less than 5 min to complete. Both forms of the PedsQL ${ }^{\mathrm{TM}}$ have established validity and reliability [21-23]. In this sample, Cronbach's alpha coefficients for the PedsQL ${ }^{\mathrm{TM}}$ generic and cancer versions were 0.89 and 0.90 , respectively.
The KPS scale was used to assess patients' functional status. KPS scores range from 0 (dead) to 100 (normal function) in 10-point increments [24]. The KPS has wellestablished validity and reliability in adults [25-28] and has been used in pediatric studies [19, 29-31].

Analytic methods

Data were analyzed using SPSS ${ }^{\circledR}$ version 15.0 (SPSS, Inc., Chicago, IL). Descriptive statistics were generated on the sample characteristics. Because HRQOL scores did not differ significantly by study site, or language, data were analyzed for the entire sample. One sample $t$ tests were used to compare total and subscale scores on the PedsQL ${ }^{\mathrm{TM}}$ between children with cancer and normative data on healthy children. Independent samples $t$ tests and Pearson's product-moment correlations were used to examine the relationships between demographic characteristics (i.e., age, gender, race/ethnicity), clinical characteristics (i.e., number of inpatient days, number of relapses, KPS scores), and symptom characteristics (i.e., number of symptoms, mean symptom severity, mean symptom distress) and generic and disease-specific measures of HRQOL. In order to control the type I error rate, a $p$ value of $<0.01$ was considered statistically significant.

\section{Results}

Demographic and clinical characteristics

The demographic and clinical characteristics of the patients $(n=61)$ are summarized in Table 1 . The majority of the children were male $(52.5 \%)$, a member of a racial/ethnic minority (63.9\%), with a mean age of 15 years, and an average KPS score of 81.7. Children were diagnosed with a wide range of cancers and $78.6 \%$ were receiving their initial treatment. Most treatment was delivered in the inpatient setting $(67.2 \%)$.

\section{Symptom characteristics}

Patients' experienced a mean of 10.6 symptoms (standard deviation $(\mathrm{SD})=4.1)$ in the prior week. Across the 31 symptoms, the mean severity and distress ratings were 0.7 and 0.6 , respectively (possible range, 0 to 4 ). The five most common symptoms were: nausea $(80.3 \%)$, fatigue $(70.5 \%)$, pain $(68.9 \%)$, alopecia (65.6\%), and feeling drowsy (57.4\%).

Differences in generic HRQOL between children with cancer and healthy children

As shown in Table 2, children with cancer reported significantly lower scores for the total score, physical 
Table 1 Demographic and clinical characteristics of the sample $(n=61)$

\begin{tabular}{|c|c|}
\hline \multicolumn{2}{|l|}{ Age (years) } \\
\hline Mean (SD) & $14.7(2.8)$ \\
\hline Range & $10-18$ \\
\hline Median & 15.3 \\
\hline \multicolumn{2}{|l|}{ Number of symptoms } \\
\hline Mean (SD) & $10.6(4.1)$ \\
\hline Range (possible range $0-31$ ) & $1-22$ \\
\hline Median & 10.0 \\
\hline \multicolumn{2}{|l|}{ Symptom severity ${ }^{\mathrm{a}}$} \\
\hline Mean (SD) & $0.7(0.4)$ \\
\hline Range (possible range $0-4$ ) & $0.1-1.7$ \\
\hline Median & 0.5 \\
\hline \multicolumn{2}{|l|}{ Symptom distress ${ }^{\mathrm{a}}$} \\
\hline Mean (SD) & $0.6(0.4)$ \\
\hline Range (possible range $0-4$ ) & $0.0-1.8$ \\
\hline Median & 0.4 \\
\hline \multicolumn{2}{|l|}{ Karnofsky performance status scores } \\
\hline Mean (SD) & $81.7(16.7)$ \\
\hline Range & $30-100$ \\
\hline Median & 90 \\
\hline \multicolumn{2}{|l|}{ Number of days hospitalized in prior week } \\
\hline Mean (SD) & $2.5(2.5)$ \\
\hline Range & $0-7$ \\
\hline Median & 2.0 \\
\hline \multicolumn{2}{|l|}{ Time since diagnosis (months) } \\
\hline Mean (SD) & $14.6(29.7)$ \\
\hline Range & $0.5-132.4$ \\
\hline Median & 3.2 \\
\hline \multicolumn{2}{|l|}{ Gender } \\
\hline Male & $32(52.5 \%)$ \\
\hline Female & $29(47.5 \%)$ \\
\hline \multicolumn{2}{|l|}{ Race/ethnicity ${ }^{\mathrm{b}}$} \\
\hline White & $22(36.1 \%)$ \\
\hline Hispanic & $23(37.7 \%)$ \\
\hline Mixed race & $7(11.5 \%)$ \\
\hline Asian & $6(9.8 \%)$ \\
\hline Black or African American & $2(3.3 \%)$ \\
\hline Native Hawaiian or other Pacific Islander & $1(1.6 \%)$ \\
\hline \multicolumn{2}{|l|}{ Diagnoses } \\
\hline Acute lymphoblastic leukemia & $15(24.5 \%)$ \\
\hline Osteosarcoma & $10(16.4 \%)$ \\
\hline Ewing sarcoma & $7(11.5 \%)$ \\
\hline Non-Hodgkin lymphoma & $7(11.5 \%)$ \\
\hline Other solid tumors & $7(11.5 \%)$ \\
\hline Central nervous system tumors & $4(6.6 \%)$ \\
\hline Rhabdomyosarcoma & $3(4.9 \%)$ \\
\hline Acute myeloid leukemia & $3(4.9 \%)$ \\
\hline Hodgkin disease & $3(4.9 \%)$ \\
\hline Other leukemia & $2(3.3 \%)$ \\
\hline
\end{tabular}

Table 1 (continued)

Number of relapses

1

$48(78.7 \%)$

$\geq 2$

$7(11.5 \%)$

$6(9.8 \%)$

Chemotherapy-administered inpatient

Yes

$41(67.2 \%)$

No

$20(32.8 \%)$

${ }^{a}$ Calculation of mean scores included zero

${ }^{\mathrm{b}}$ Race/ethnicity reported by parents

functioning, and school functioning subscales of the PedsQL ${ }^{\mathrm{TM}}$ than the normative sample of healthy children [32]. No between group differences were found for the emotional functioning and social functioning subscales. In addition, previously established criteria for clinically meaningful decreases in PedsQL ${ }^{\mathrm{TM}}$ GCS scores [32] are listed in Table 2. These criteria were met for the total, physical functioning, and school functioning scores.

Relationships between demographic characteristics and generic and disease-specific measures of HRQOL

As shown in Table 3, no significant differences were found between age groups, genders, and race/ethnicity groups on any total or subscale scores for the generic or disease specific measures of HRQOL.

Relationships between clinical characteristics and generic and disease-specific measures of HRQOL

As shown in Table 4, the only HRQOL score that was correlated with the number of days hospitalized in the past week was nausea, such that children who were hospitalized longer reported higher levels of nausea. No significant relationships were found between number of relapses and any of the HRQOL scores. KPS scores were positively correlated with the total and most of the subscale scores of the generic HRQOL measure (i.e., all subscales except emotional functioning and school functioning) and with the total and nausea subscale of the disease-specific measure.

Relationships between symptom characteristics and generic and disease-specific measures of HRQOL

The total and subscale scores for the PedsQL ${ }^{\text {TM }} 3.0$ Cancer module, for this sample, are illustrated in Fig. 1. As shown in Table 4, significant negative correlations were found between the total number of symptoms and the total and all of the subscale scores of the generic HRQOL measure 
Table 2 Differences in PedsQL 4.0 generic core scales between oncology patients and a normative sample of children

\begin{tabular}{|c|c|c|c|c|c|c|c|c|c|c|c|c|}
\hline \multirow[b]{2}{*}{ Dimension } & \multicolumn{5}{|c|}{ Oncology sample } & \multicolumn{7}{|c|}{ Normative data ${ }^{\mathrm{a}, \mathrm{b}}$} \\
\hline & $\mathrm{N}$ & Mean & SD & $\begin{array}{l}\text { Percent 1SD } \\
\text { below } \\
\text { normative mean }\end{array}$ & $\begin{array}{l}\text { Percent 2SD } \\
\text { below } \\
\text { normative mean }\end{array}$ & $\mathrm{N}$ & Mean & SD & $t$ & $p$ value & $\begin{array}{l}\text { Effect } \\
\text { size }\end{array}$ & $\begin{array}{l}\text { Minimal clinically } \\
\text { important } \\
\text { difference }^{\mathrm{a}}\end{array}$ \\
\hline Total score & 60 & 68.0 & 17.3 & $43.3 \%$ & $31.7 \%$ & 5,079 & 83.91 & 12.47 & -7.12 & $<0.001$ & 1.27 & 4.36 \\
\hline Physical functioning & 61 & 57.7 & 23.7 & $78.7 \%$ & $57.4 \%$ & 5,070 & 87.77 & 13.12 & -9.89 & $<0.001$ & 2.26 & 6.66 \\
\hline Emotional functioning & 61 & 76.1 & 21.8 & $27.9 \%$ & $9.8 \%$ & 5,068 & 79.21 & 18.02 & -1.13 & 0.265 & 0.17 & 8.94 \\
\hline Social functioning & 60 & 81.7 & 15.7 & $18.3 \%$ & $5.0 \%$ & 5,056 & 84.97 & 16.71 & -1.63 & 0.109 & 0.20 & 8.36 \\
\hline School functioning & 53 & 63.4 & 25.6 & $54.7 \%$ & $26.4 \%$ & 5,026 & 81.31 & 16.09 & -4.80 & $<0.001$ & 1.10 & 9.12 \\
\hline
\end{tabular}

$S D$ standard deviation

${ }^{\text {a }}$ Data from Varni et al. [32];

${ }^{\mathrm{b}}$ Effect size calculation: (normative mean-oncology mean)/pooled SD

except the school functioning subscale, such that a higher number of symptoms was associated with poorer HRQOL. In terms of the cancer-specific measure, significant negative correlations were found between total number of symptoms and the total score and nausea subscale scores. A similar pattern was noted for mean symptom severity.

Signficant negative correlations were found between symptom distress and the total and most of the subscale scores of the generic HRQOL measure except the school functioning subscale. For the cancer-specific module, significant negative correlations were found between symptom distress and the total score and nausea and cognitive problems subscale scores.

\section{Discussion}

To our knowledge, this study is the first to describe the relationships between functional status and a number of symptom characteristics and generic and disease-specific measures of HRQOL in a relatively homogeneous sample of children who underwent myelosuppressive CTX. The effect sizes for differences in pediatric oncology patients' physical subscale scores compared to those of healthy children were greater than for the psychosocial subscales. Based on a cutoff score of 1 SD below the population norm, over $75 \%$ of children in this study met this cutoff for the physical functioning subscale score and over $25 \%$ met this cutoff for the total, emotional functioning, and school functioning scores (Table 2). In addition, for the total, physical functioning, and school functioning scores, these differences met previously established criteria for clinically meaningful decreases in HRQOL [32]. These findings are similar to those reported for children with brain tumors during their first year after diagnosis [17], children with brain tumors on and off treatment [33], and for a heterogeneous sample of children receiving active treatment for cancer [15].

An interesting finding from this study, that is consistent with previous reports, is that no between group differences were found in children's scores on the emotional [17, 33] and social functioning [17] subscales of the PedsQL ${ }^{\text {TM }}$ generic version. Our quantitative data support the hypothesis proposed by Penn et al. [17], that children with cancer may not understand the consequences of their malignancy; may repress symptoms of emotional distress; or may be reluctant to provide details of their emotional state [17]. Alternatively, children with cancer may develop an astounding degree of resiliency [34]. Additional investigations are warranted, perhaps using qualitative research methods that explore the impact of cancer and its treatment on children's emotional and social functioning.

In terms of the cancer-specific HRQOL measure, the worst scores reported were for nausea (68.9), worry (69.5), and pain and hurt (72.3). Only three studies have reported subscale scores on the PedsQL ${ }^{\mathrm{TM}}$ cancer module from children during CTX [11, 23, 35]. Our findings are similar to most of those reported in previous studies. However, children in this study reported less nausea and procedural anxiety than Brazilian children on CTX [35]. The supportive care interventions readily available in the United States (e.g., general anesthesia during invasive procedures, more routine use of antiemetics) may explain these differences. In addition, compared to data from Varni et al. [23], our sample reported less procedural anxiety than children on CTX in the late 1990s. General anesthesia was not commonly used for invasive procedures at that time. Future studies need to evaluate HRQOL in relationship to various supportive care measures and how these scores change over the course of cancer treatment and into survivorship.

The lack of many gender [36-38] and racial/ethnic differences [39] in generic and disease-specific dimensions 
Table 3 Relationships among PedsQL ${ }^{\mathrm{TM}}$ total and subscale scores and demographic characteristics

\begin{tabular}{|c|c|c|c|c|c|c|}
\hline & \multicolumn{2}{|l|}{ Age } & \multicolumn{2}{|l|}{ Gender } & \multicolumn{2}{|l|}{ Race } \\
\hline & $<13$ years & $\geq 13$ years & Male & Female & White & Others \\
\hline & \multicolumn{6}{|c|}{ PedsQL ${ }^{\text {TM }} 4.0$ Generic Core Scales } \\
\hline \multirow[t]{2}{*}{ Total score } & $67.9(16.5)$ & $68.1(17.9)$ & $68.9(17.1)$ & $67.1(17.7)$ & $65.2(17.3)$ & $69.7(17.3)$ \\
\hline & $t=0.05$ & $p=0.96$ & $t=0.40$ & $p=0.69$ & $t=-0.96$ & $p=0.34$ \\
\hline \multirow[t]{2}{*}{ Physical functioning } & $56.4(21.3)$ & $58.4(25.0)$ & $58.1(24.6)$ & $57.3(23.2)$ & $53.3(24.0)$ & $60.2(23.5)$ \\
\hline & $t=0.31$ & $p=0.76$ & $t=0.13$ & $p=0.90$ & $t=-1.10$ & $p=0.28$ \\
\hline \multirow[t]{2}{*}{ Emotional functioning } & $77.8(24.8)$ & $75.2(20.5)$ & $76.4(21.4)$ & $75.7(22.6)$ & $75.5(21.3)$ & $76.4(22.4)$ \\
\hline & $t=-0.42$ & $p=0.68$ & $t=0.13$ & $p=0.90$ & $t=-0.16$ & $p=0.87$ \\
\hline \multirow[t]{2}{*}{ Social functioning } & $81.8(13.9)$ & $81.6(16.7)$ & $81.3(16.3)$ & $82.1(15.4)$ & $80.2(18.5)$ & $82.5(14.1)$ \\
\hline & $t=-0.03$ & $p=0.98$ & $t=-0.22$ & $p=0.83$ & $t=-0.54$ & $p=0.59$ \\
\hline \multirow[t]{3}{*}{ School functioning } & $62.5(23.5)$ & $65.6(27.1)$ & $66.4(25.9)$ & $62.2(25.6)$ & $57.3(24.6)$ & $68.8(25.6)$ \\
\hline & $t=0.43$ & $p=0.67$ & $t=0.60$ & $p=0.55$ & $t=-1.62$ & $p=0.11$ \\
\hline & PedsQLTM 3 & ncer Module & & & & \\
\hline \multirow[t]{2}{*}{ Total score } & $77.6(14.3)$ & $75.9(14.9)$ & $77.6(15.8)$ & $75.3(13.4)$ & $76.3(17.9)$ & $76.6(12.7)$ \\
\hline & $t=-0.42$ & $p=0.67$ & $t=0.60$ & $p=0.55$ & $t=-0.09$ & $p=0.93$ \\
\hline \multirow[t]{2}{*}{ Pain and hurt } & $79.4(20.4)$ & $68.9(28.9)$ & $76.2(26.3)$ & $68.1(27.1)$ & $67.0(33.5)$ & $75.3(21.9)$ \\
\hline & $t=-1.45$ & $p=0.15$ & $t=1.18$ & $p=0.24$ & $t=-1.17$ & $p=0.25$ \\
\hline \multirow[t]{2}{*}{ Nausea } & $72.0(19.1)$ & $67.3(25.7)$ & $66.6(27.0)$ & $71.4(19.6)$ & $65.0(25.5)$ & $71.0(22.7)$ \\
\hline & $t=-0.72$ & $p=0.47$ & $t=-0.79$ & $p=0.43$ & $t=-0.95$ & $p=0.34$ \\
\hline \multirow[t]{2}{*}{ Procedural anxiety } & $67.5(28.3)$ & $77.6(29.0)$ & $83.6(23.5)$ & $64.1(31.3)$ & $72.7(33.8)$ & $75.2(26.2)$ \\
\hline & $t=1.29$ & $p=0.20$ & $t=2.73$ & $p=0.01$ & $t=-0.32$ & $p=0.75$ \\
\hline \multirow[t]{2}{*}{ Treatment anxiety } & $89.2(20.6)$ & $82.5(24.4)$ & $83.3(25.5)$ & $86.3(20.8)$ & $81.8(29.3)$ & $86.4(19.2)$ \\
\hline & $t=-1.05$ & $p=0.30$ & $t=-0.49$ & $p=0.63$ & $t=-0.73$ & $p=0.47$ \\
\hline \multirow[t]{2}{*}{ Worry } & $74.6(25.6)$ & $67.1(24.8)$ & $66.9(26.7)$ & $72.4(23.3)$ & $72.3(28.2)$ & $67.9(23.4)$ \\
\hline & $t=-1.10$ & $p=0.28$ & $t=-0.85$ & $p=0.40$ & $t=0.66$ & $p=0.52$ \\
\hline \multirow[t]{2}{*}{ Cognitive problems } & $83.8(15.8)$ & $78.8(15.8)$ & $80.9(15.5)$ & $79.8(16.5)$ & $78.4(16.9)$ & $81.5(15.3)$ \\
\hline & $t=-1.16$ & $p=0.25$ & $t=0.28$ & $p=0.78$ & $t=-0.73$ & $p=0.47$ \\
\hline \multirow[t]{2}{*}{ Perceived physical appearance } & $80.8(25.5)$ & $83.5(17.4)$ & $87.5(17.3)$ & $77.3(22.1)$ & $90.5(13.2)$ & $78.2(22.3)$ \\
\hline & $t=0.49$ & $p=0.63$ & $t=2.01$ & $p=0.05$ & $t=2.72$ & $p=0.01$ \\
\hline \multirow[t]{2}{*}{ Communication } & $74.2(26.5)$ & $83.5(20.7)$ & $80.2(24.8)$ & $80.7(21.1)$ & $85.2(20.1)$ & $77.8(24.3)$ \\
\hline & $t=1.51$ & $p=0.14$ & $t=-0.09$ & $p=0.93$ & $t=1.22$ & $p=0.23$ \\
\hline
\end{tabular}

of HRQOL are consistent with previous reports of children with cancer who received CTX. To date, only four studies have identified gender differences in HRQOL. Girls reported lower HRQOL scores than boys on various subscales in three of these four studies [15, 39, 40]. In addition, in two studies [36, 37], white children reported better HRQOL than children from racial/ethnic minority groups. While a few studies found that older children reported a poorer HRQOL, these differences were generally in the psychosocial dimensions [15, 37, 41-43], and were contradicted by other studies [36, 39, 42]. These inconsistent findings may relate to variations in the HRQOL instruments used, comparisons between children's selfreports and proxy reports, and small sample sizes. While few differences in HRQOL were noted when demographic characteristics were compared in a large population-based study of the PedsQL ${ }^{\text {TM }}$ [32], these inconsistent findings in oncology patients warrant additional investigation.

In terms of clinical characteristics, while the number of days hospitalized and the number of relapses were not associated with any generic or disease-specific dimensions of HRQOL except nausea, children with lower KPS scores reported significantly poorer scores on almost every generic dimension of HRQOL. The strongest correlations were found with the physical and social functioning dimensions of the generic measure. Clinicians' familiarity with the KPS, its simplicity of use, and the strong correlations with HRQOL make it an ideal metric to include in additional HRQOL research.

The moderate correlations between the various symptom characteristics and the various dimensions of the generic 
Table 4 Relationships among PedsQL ${ }^{\mathrm{TM}}$ scores and clinical and symptom characteristics

\begin{tabular}{llllllllllll}
\hline & $\begin{array}{l}\text { Number of days } \\
\text { hospitalized in } \\
\text { prior week }\end{array}$ & $\begin{array}{l}\text { Number of } \\
\text { relapses }\end{array}$ & KPS score & $\begin{array}{l}\text { Number of } \\
\text { symptoms }\end{array}$ & $\begin{array}{l}\text { Mean symptom } \\
\text { severity }\end{array}$ & $\begin{array}{l}\text { Mean symptom } \\
\text { distress }\end{array}$ \\
& PedsQL & & & &
\end{tabular}

HRQOL measure suggest that the total number of symptoms, as well as severity and distress associated with these symptoms have a negative effect on children's HRQOL. On average, children in this study reported ten symptoms in the week following the administration of CTX. While the mean symptom severity (0.7) and distress (0.6) scores were relatively low, these scores included ratings on all 31 symptoms with zeros for symptoms that were not present.

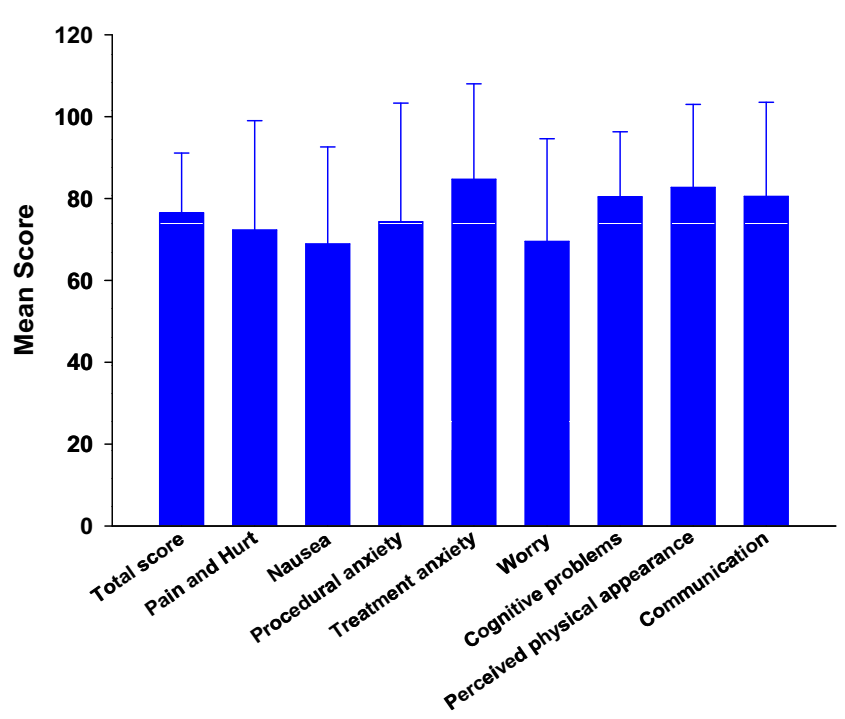

Fig. 1 Patients' scores on the PedsQL ${ }^{\mathrm{TM}}$ 3.0 Cancer Module, completed 1 week after myelosuppressive chemotherapy. All values are plotted as means \pm standard deviations
Our findings are consistent with previous reports that found that higher symptom severity and interference scores were associated with poorer HRQOL in a sample of children who were on and off therapy [19], as well as in a study of adolescents and young adults with cancer and blood disorders [44].

A study of the associations between symptom characteristics and HRQOL poses some conceptual challenges. First, the issue of the causal relationships between symptom number, severity, and distress and decrements in HRQOL are difficult to differentiate. Clearly, some symptoms may cause decrements in HRQOL (e.g., nausea may cause poor HRQOL). However, HRQOL may also affect symptom occurrence (e.g., insomnia or anxiety may be caused by decrements in the social functioning or school functioning dimensions of HRQOL) [45]. In addition, many HRQOL measures, like the measure used in this study, include one or more dimensions that evaluate symptoms. Future studies that include a longitudinal evaluation of both symptom characteristics and various dimensions of HRQOL and the use of more sophisticated statistical techniques may be able to determine cause and effect relationships.

Several study limitations need to be acknowledged. The relatively small sample size and heterogeneous population limited the use of multivariate methods to predict decrements in HRQOL. Despite these limitations, this study adds to the growing body of knowledge of the factors that affect HRQOL. Future research should focus on patients who are similar with respect to diagnosis and treatment regimen, 
and time since diagnosis in order to eliminate potential confounding factors. Such a study, with national or international collaborations, would further delineate the factors that affect HRQOL in order to identify children who are at higher risk for decrements in HRQOL and to be better able to initiate optimal treatment regimens for these children during cancer CTX.

Open Access This article is distributed under the terms of the Creative Commons Attribution Noncommercial License which permits any noncommercial use, distribution, and reproduction in any medium, provided the original author(s) and source are credited.

\section{References}

1. Spieth LE, Harris CV (1996) Assessment of health-related quality of life in children and adolescents: an integrative review. J Pediatr Psychol 21:175-193

2. Osoba D (1999) Interpreting the meaningfulness of changes in health-related quality of life scores: lessons from studies in adults. Int J Cancer Suppl 12:132-137

3. Bradlyn AS, Harris CV, Spieth LE (1995) Quality of life assessment in pediatric oncology: a retrospective review of phase III reports. Soc Sci Med 41:1463-1465

4. Buchanan DR, O'Mara AM, Kelaghan JW, Minasian LM (2005) Quality-of-life assessment in the symptom management trials of the National Cancer Institute-supported Community Clinical Oncology Program. J Clin Oncol 23:591-598

5. US Department of Health and Human Services FDA Center for Drug Evaluation and Research, US Department of Health and Human Services FDA Center for Biologics Evaluation and Research, US Department of Health and Human Services FDA Center for Devices and Radiological Health (2006) Guidance for industry: patient-reported outcome measures: use in medical product development to support labeling claims: draft guidance Health Qual Life Outcomes 4:79

6. Gotay CC, Kawamoto CT, Bottomley A, Efficace F (2008) The prognostic significance of patient-reported outcomes in cancer clinical trials. J Clin Oncol 26:1355-1363

7. Nathan PC, Furlong W, Barr RD (2004) Challenges to the measurement of health-related quality of life in children receiving cancer therapy. Pediatr Blood Canc 43:215-223

8. Banks BA, Barrowman NJ, Klaassen R (2008) Health-related quality of life: changes in children undergoing chemotherapy. J Pediatr Hematol Oncol 30:292-297

9. Barr RD, Petrie C, Furlong W, Rothney M, Feeny D (1997) Health-related quality of life during post-induction chemotherapy in children with acute lymphoblastic leukemia in remission: an influence of corticosteroid therapy. Int J Oncol 11:333-339

10. Barrera M, Wayland L-A, D'Agostino NM, Gibson J, Weksberg R, Malkin D (2003) Developmental differences in psychological adjustment and health-related quality of life in pediatric cancer patients. Children's Health Care 32:215-232

11. de Vries MA, van Litsenburg RR, Huisman J, Grootenhuis MA, Versluys AB, Kaspers GJ, Gemke RJ (2008) Effect of dexamethasone on quality of life in children with acute lymphoblastic leukaemia: a prospective observational study. Health Qual Life Outcomes 6:103

12. Eiser C, Davies H, Jenney M, Stride C, Glaser A (2006) HRQOL implications of treatment with dexamethasone for children with acute lymphoblastic leukemia (ALL). Pediatr Blood Canc 46:35-39
13. Stevens B, Croxford R, McKeever P, Yamada J, Booth M, Daub S, Gafni A, Gammon J, Greenberg M (2006) Hospital and home chemotherapy for children with leukemia: a randomized crossover study. Pediatr Blood Canc 47:285-292

14. Sung L, Greenberg ML, Doyle JJ, Young NL, Ingber S, Rubenstein J, Wong J, Samanta T, McLimont M, Feldman BM (2003) Construct validation of the Health Utilities Index and the Child Health Questionnaire in children undergoing cancer chemotherapy. Br J Cancer 88:1185-1190

15. Sung L, Klaassen RJ, Dix D, Pritchard S, Yanofsky R, Dzolganovski B, Almeida R, Klassen A (2009) Identification of paediatric cancer patients with poor quality of life. Br J Cancer 100:82-88

16. Waters EB, Wake MA, Hesketh KD, Ashley DM, Smibert E (2003) Health-related quality of life of children with acute lymphoblastic leukaemia: comparisons and correlations between parent and clinician reports. Int J Cancer 103:514-518

17. Penn A, Lowis SP, Hunt LP, Shortman RI, Stevens MC, McCarter RL, Curran AL, Sharples PM (2007) Health related quality of life in the first year after diagnosis in children with brain tumours compared with matched healthy controls; a prospective longitudinal study. Eur J Cancer 44:1243-1252

18. Sung L, Young NL, Greenberg ML, McLimont M, Samanta T, Wong J, Rubenstein J, Ingber S, Doyle JJ, Feldman BM (2004) Health-related quality of life (HRQL) scores reported from parents and their children with chronic illness differed depending on utility elicitation method. J Clin Epidemiol 57:1161-1166

19. Tseng TH, Cleeland CS, Wang XS, Lin CC (2008) Assessing cancer symptoms in adolescents with cancer using the Taiwanese version of the M. D. Anderson Symptom Inventory. Cancer Nurs 31:E9-E16

20. Collins JJ, Byrnes ME, Dunkel IJ, Lapin J, Nadel T, Thaler HT, Polyak T, Rapkin B, Portenoy RK (2000) The measurement of symptoms in children with cancer. J Pain Symptom Manage 19:363-377

21. Varni JW, Limbers CA, Burwinkle TM (2007) How young can children reliably and validly self-report their health-related quality of life?: an analysis of 8, 591 children across age subgroups with the PedsQL 4.0 Generic Core Scales. Health Qual Life Outcomes $5: 1$

22. Varni JW, Seid M, Kurtin PS (2001) PedsQL 4.0: reliability and validity of the Pediatric Quality of Life Inventory version 4.0 generic core scales in healthy and patient populations. Med Care 39:800-812

23. Varni JW, Burwinkle TM, Katz ER, Meeske K, Dickinson P (2002) The PedsQL in pediatric cancer: reliability and validity of the Pediatric Quality of Life Inventory Generic Core Scales, Multidimensional Fatigue Scale, and Cancer Module. Cancer 94:2090-2106

24. Karnofsky D, Burchenal J (1949) The clinical evaluation of chemotherapeutics in cancer. In: Macleod CM (ed) Evaluation of chemotherapeutic agents; Symposia of the Section on Microbiology, the New York Academy of Medicine. Columbia University Press, New York, pp 191-205

25. Firat S, Bousamra M, Gore E, Byhardt RW (2002) Comorbidity and KPS are independent prognostic factors in stage I non-smallcell lung cancer. Int J Radiat Oncol Biol Phys 52:1047-1057

26. Mor V, Laliberte L, Morris JN, Wiemann M (1984) The Karnofsky Performance Status Scale. An examination of its reliability and validity in a research setting. Cancer 53:2002-2007

27. Schaafsma J, Osoba D (1994) The Karnofsky Performance Status Scale re-examined: a cross-validation with the EORTC-C30. Qual Life Res 3:413-424

28. Schag CC, Heinrich RL, Ganz PA (1984) Karnofsky performance status revisited: reliability, validity, and guidelines. J Clin Oncol 2:187-193 
29. Forinder U, Lof C, Winiarski J (2006) Quality of life following allogeneic stem cell transplantation, comparing parents' and children's perspective. Pediatr Transplant 10:491-496

30. Jalali R, Dutta D, Kamble R, Gupta T, Munshi A, Sarin R, Dinshaw K (2008) Prospective assessment of activities of daily living using modified Barthel's Index in children and young adults with low-grade gliomas treated with stereotactic conformal radiotherapy. J Neurooncol 90:321-328

31. Williams PD, Schmideskamp J, Ridder EL, Williams AR (2006) Symptom monitoring and dependent care during cancer treatment in children: pilot study. Cancer Nurs 29:188-197

32. Varni JW, Burwinkle TM, Seid M, Skarr D (2003) The PedsQL 4.0 as a pediatric population health measure: feasibility, reliability, and validity. Ambul Pediatr 3:329-341

33. Palmer SN, Meeske KA, Katz ER, Burwinkle TM, Varni JW (2007) The PedsQL Brain Tumor Module: initial reliability and validity. Pediatr Blood Canc 49:287-293

34. Haase JE (2004) The adolescent resilience model as a guide to interventions. J Pediatr Oncol Nurs 21:289-299, discussion 300-284

35. Scarpelli AC, Paiva SM, Pordeus IA, Ramos-Jorge ML, Varni JW, Allison PJ (2008) Measurement properties of the Brazilian version of the Pediatric Quality of Life Inventory (PedsQL) cancer module scale. Health Qual Life Outcomes 6:7

36. Russell KM, Hudson M, Long A, Phipps S (2006) Assessment of health-related quality of life in children with cancer: consistency and agreement between parent and child reports. Cancer 106:2267-2274

37. Shankar S, Robison L, Jenney ME, Rockwood TH, Wu E, Feusner J, Friedman D, Kane RL, Bhatia S (2005) Health-related quality of life in young survivors of childhood cancer using the MinneapolisManchester Quality of Life-Youth Form. Pediatrics 115:435-442

38. Varni JW, Burwinkle TM, Katz ER (2004) The PedsQL in pediatric cancer pain: a prospective longitudinal analysis of pain and emotional distress. J Dev Behav Pediatr 25:239-246

39. Meeske K, Katz ER, Palmer SN, Burwinkle T, Varni JW (2004) Parent proxy-reported health-related quality of life and fatigue in pediatric patients diagnosed with brain tumors and acute lymphoblastic leukemia. Cancer 101:2116-2125

40. Kiernan G, Gormley M, MacLachlan M (2004) The RevisedPerceived Illness Experience Scale (R-PIE): data from the Barretstown studies. Behav Med 30:23-31

41. Bhat SR, Goodwin TL, Burwinkle TM, Lansdale MF, Dahl GV, Huhn SL, Gibbs IC, Donaldson SS, Rosenblum RK, Varni JW, Fisher PG (2005) Profile of daily life in children with brain tumors: an assessment of health-related quality of life. J Clin Oncol 23:5493-5500

42. Landolt MA, Vollrath M, Niggli FK, Gnehm HE, Sennhauser FH (2006) Health-related quality of life in children with newly diagnosed cancer: a one year follow-up study. Health Qual Life Outcomes 4:63

43. Razzouk BI, Hord JD, Hockenberry M, Hinds PS, Feusner J, Williams D, Rackoff WR (2006) Double-blind, placebo-controlled study of quality of life, hematologic end points, and safety of weekly epoetin alfa in children with cancer receiving myelosuppressive chemotherapy. J Clin Oncol 24:3583-3589

44. Ewing JE, King MT, Smith NF (2009) Validation of modified forms of the PedsQL generic core scales and cancer module scales for adolescents and young adults (AYA) with cancer or a blood disorder. Qual Life Res 18:231-244

45. Osoba D (2007) Translating the science of patient-reported outcomes assessment into clinical practice. J Natl Cancer Inst Monogr 37:5-11

This research was supported by a grant from the National Institute of Nursing Research (NR010600). Dr. Baggott received support from the American Cancer Society, the Betty Irene Moore Doctoral Fellowship in Nursing, and the Oncology Nursing Foundation. 